\title{
Relationship Between Circulating Tumor Cells and Tissue Plasminogen Activator in Patients with Early Breast Cancer
}

\author{
BRANISLAV B YSTRICKY ${ }^{1,2}$, SILVIA JURISOVA ${ }^{1,3}$, MARIAN KARABA $^{3,4}$, GABRIEL MINARIK $^{5}$, \\ JURAJ BENCA ${ }^{3,6}$, TATIANA SEDLÁCKOVÁ ${ }^{5}$, LUBOMIRA TOTHOVA ${ }^{5}$, BARBORA VLKOVA ${ }^{5}$, \\ ZUZANA CIERNA $^{7}$, PAVOL JANEGA ${ }^{7,8}$, DENISA MANASOVA ${ }^{9}$, PAULINA GRONESOVA ${ }^{10}$, \\ DANIEL PINDAK ${ }^{3,4}$, JOZEF MARDIAK $^{1,3}$, PETER CELEC $^{5}$ and MICHAL MEGO ${ }^{1,3,9}$ \\ ${ }^{1}$ Second Department of Medical Oncology, ${ }^{5}$ Institute of Molecular Biomedicine, ${ }^{7}$ Department of Pathology, and \\ ${ }^{9}$ Translational Research Unit, Faculty of Medicine, Comenius University, Bratislava, Slovakia; \\ ${ }^{2}$ Department of Oncology, Faculty Hospital Trencin, Trencin, Slovakia; \\ ${ }^{3}$ National Cancer Institute, Bratislava, Slovakia; \\ ${ }^{4}$ Department of Surgery, Slovak Medical University, Bratislava, Slovakia; \\ ${ }^{6}$ Department of Medicine, St. Elizabeth University, Bratislava, Slovakia; \\ ${ }^{8}$ Institute of Normal and Pathological Physiology, Bratislava, Slovakia; \\ ${ }^{10}$ Cancer Research Institute, Slovak Academy of Sciences, Bratislava, Slovakia
}

\begin{abstract}
Aim: Cancer increases the risk of venous thromboembolism (VTE) and circulating tumor cells (CTCS) are associated with an increased risk of VTE and, thus, with increased D-dimers as a product of fibrinolysis. Tissue plasminogen activator (TPA) is one of the key enzymes in the fibrinolytic pathway. Its activity is crucial in maintaining the balance between blood coagulation and fibrinolysis. This study aimed to analyze the association between CTCs and tPA in patients with primary breast cancer before surgery. Patients and Methods: This prospective study included 110 patients in whom CTCs were detected by quantitative reverse transcription polymerase chain reaction targeted at epithelial (CK19) or epithelial-mesenchymal transition (EMT)associated genes[TWIST1, SNAI1, SNAI2, zinc finger E-boxbinding homeobox 1 (ZEB1), forkhead box protein $C 2$ (FOXC2)]. Plasma tPA protein was detected using enzymelinked immunosorbent assay (ELISA). Results: CTCs were detected in 31 (28.2\%) patients. There was no association between plasma tPA and CTCs. Although on average, higher levels of tPA were detected in patients with CTCs expressing EMT-associated genes, this difference did not reach statistical
\end{abstract}

Correspondence to: Michal Mego, 2nd Department of Medical Oncology, Comenius University, Faculty of Medicine and National Cancer Institute, Klenova 1, 83310 Bratislava, Slovak Republic. Tel: +421 259378366, Fax: +421 254774943, e-mail: misomego@ gmail.com

Key Words: Breast cancer, circulating tumor cells, tissue plasminogen activator. significance. There was no association of plasma tPA with any of the observed patient or tumor characteristics. Conclusion: Even though the blood coagulation pathway may be activated in more aggressive disease related to an elevated CTC count, in this study, we did not find any association between CTCs and plasma concentrations of tPA.

Venous thromboembolic events (VTEs) are a frequent complication in patients with cancer (1). Evidence suggests that their absolute risk of VTE depends on the tumor type, stage or its extent, as well as on its treatment with antineoplastic agents (2). Tumor cells can activate hemostasis/fibrinolytic systems by several mechanisms, including production of pro-coagulant and pro-aggregating factors or facilitating conversion of plasminogen to plasmin (3). Circulating tumor cells (CTCs) play a central role in the metastatic cascade. The prognostic value of CTCs in early breast cancer has been reported $(4,5)$. CTCs represent a heterogeneous cell population with different phenotypes and, thus, with a multitude of pathophysiological consequences (6).

CTCs, either directly or indirectly, are associated with a prothrombotic state. Previously, we demonstrated that the presence of any number of CTCs in peripheral blood of patients with metastatic breast cancer is associated with an increased risk of VTE (7). More recently, we found a positive correlation of plasma D-dimers, urokinase plasminogen activator proteins (UPA) and CTCs in patients with early, as well as those with metastatic breast cancer $(8,9)$. Tissue plasminogen activator (tPA) is one of the key enzymes in the fibrinolytic pathway. Its activity is crucial for the maintenance of balance between blood coagulation and fibrinolysis. 
During fibrinolysis, tPA and uPA convert plasminogen to plasmin, which cleaves the fibrin network and releases fibrin degradation products such as D-dimers. In patients with cancer, the uPA system is associated with degradation of the extracellular matrix and invasion of tumor cells into the surrounding tissues, facilitating distant spread. Patients with early breast cancer and any detection of CTCs had higher levels of plasma uPA, but we found no correlation between D-dimers, tissue factor or plasminogen activator inhibitor-1 (PAI-1) and uPA in our previous work (8). Hence, we turned our attention to tPA, another glycoprotein that is involved in fibrinolysis and is associated with an aggressive phenotype (10).

The aim of this study was to analyze potential associations between tPA as a marker of fibrinolysis and CTCs. As an extension to our previous work, we hypothesized that there is a positive correlation between CTCs and TPA in patients with early breast cancer treated with primary surgery.

\section{Patients and Methods}

This is an extension to our previous translational study (Protocol TRUSK 002) approved by the Institutional Review Board (IRB) of the National Cancer Institute of Slovakia as reported previously $(11,12)$. Briefly, the study included 110 patients with stage I-III primary breast cancer with planned definitive surgery. From each patient, peripheral blood samples for CTC detection and plasma analysis were collected. Data regarding age, tumor stage, histology, regional lymph node involvement, hormone receptor status and human epidermal growth factor receptor 2 (HER2) status were recorded for each patient. Agematched healthy women donors $(\mathrm{N}=60)$ without breast cancer were recruited and consented according to the IRB-approved protocol.

Plasma isolation. Venous peripheral blood samples were collected in EDTA-treated tubes and centrifuged at $1,000 \times g$ for $10 \mathrm{~min}$ at room temperature within $2 \mathrm{~h}$ of venipuncture. To avoid cellular contamination, plasma was carefully harvested and centrifuged again at $1000 \times g$ for $10 \mathrm{~min}$ at room temperature. The cell-free plasma samples were cryopreserved at $-80^{\circ} \mathrm{C}$ until further analyses.

Detection of CTCs in peripheral blood. CTCs were detected in peripheral blood depleted of CD45+ leukocytes by a quantitative realtime polymerase chain reaction (RT-PCR) based assay, as described previously $(11,12)$. Briefly, blood samples were depleted of CD45+ leukocytes using RossetteSep ${ }^{\mathrm{TM}}$ kit (StemCell Technologies, Vancouver, BC, Canada). Isolated RNA from CD45-depleted samples was reversed transcribed to cDNA and subsequently subjected to qRTPCR for expression of epithelial (CK19) or epithelial-mesenchymal transition (EMT) genes (TWIST1, SNAI1, SNAI2, zinc finger E-boxbinding homeobox 1 (ZEB1)].

Patient samples with a higher number of keratin-19 (KRT19) gene transcripts than those of healthy donors were scored as epithelial CTC-positive (CTC_EP), while patient samples with a higher number of EMT-inducing transcription factors (TWIST1, SNAI1, $S N A I 2$ and ZEB1) gene transcripts than those of healthy donors were scored as CTC_EMT-positive. Expression of at least one of the markers (either epithelial or mesenchymal) at levels above the defined cutoff was sufficient to define a sample as CTC-positive.
Patient samples with $C K 19$ gene transcripts higher than those of healthy donors were scored as epithelial CTC (CTC_EP)-positive, while patient samples with higher EMT gene transcripts than those of healthy donors were scored as CTC_EMT-positive.

Measurement of tPA in plasma. Plasma tPA was analyzed using a commercial enzyme-linked immunosorbent assay (ELISA). Human tPA ELISA kit (Assaypro LLC, St. Charles, MO, USA) was used according to the instructions of the manufacturer. The sensitivity of the kit is $0.03 \mathrm{ng} / \mathrm{ml}$. The intra- and inter-assay coefficients of variation are below $5 \%$ and $10 \%$, respectively. Concentrations (ng per $\mathrm{ml}$ ) were calculated according to a near-linear calibration curve.

Statistical analysis. The characteristics of the cohort were summarized using the median (range) for continuous variables and frequency (percentage) for categorical variables. Normality of distribution was tested using the Kolmogorov-Smirnoff test. For normally distributed data, differences between the groups were tested using the Student $t$ test or analysis of variance (ANOVA) with corrections according to Bonferroni or Tamhane depending on the homogeneity of variance. The nonparametric Mann-Whitney $U$-test was used for non-normally distributed data. Pearson or Spearman correlations test was used according to the normality of data. Categorical data were tested using the Fisher's exact test or chi-square test. All $p$-values presented are two-sided and were considered significant if less than 0.05. Statistical analyses were performed using NCSS 2007 Data Analysis software (NCCS LLC, Kaysville, UT, USA).

\section{Results}

The study population consisted of 110 patients with primary breast cancer with a median age of 60 years (range $=35-83$ years). Detailed characteristics of the patients are shown in Table I. The majority of patients had tumors smaller than $2 \mathrm{~cm}$, negative axillary lymph nodes $(60 \%)$, positive for hormone receptors and negative for HER2 (85\% and 83\%, respectively).

CTC detection. Overall, CTCs were detected in 31 (28.2\%) patients. CTC_EP were present in the peripheral blood of 16 (14.6\%) patients; CTC_EMT were present in 19 (17.3\%) patients, while in four (3.6\%) patients, CTCs exhibited both epithelial and mesenchymal markers (Table I).

CTCs and plasma tPA. The presence of CTCs was not associated with plasma tPA. Although a slightly higher average plasma tPA was found in patients with CTC_EMT $(8.28$ vs. $6.5 \mathrm{ng} / \mathrm{ml})$, this difference did not reach statistical significance. Similarly, no association with tPA was found for tumor stage, grade, histology, hormone, or HER2 status, nor with Ki67 index as a cell-proliferation marker (Table II).

Plasma tPA and other markers of coagulation. In our previous work, we showed that presence of CTCs in peripheral blood of patients with early breast cancer is associated with higher plasma D-dimer levels, but not with tissue uPA, tissue factor or PAI-1. As tPA is involved in fibrin degradation, we tested 
Table I. Characteristics of the patients included in this study.

\begin{tabular}{|c|c|c|}
\hline Characteristic & $\mathrm{N}$ & $\%$ \\
\hline All patients & 110 & 100.0 \\
\hline \multicolumn{3}{|l|}{ T-Stage } \\
\hline 1 & 67 & 60.9 \\
\hline$>1$ & 43 & 39.1 \\
\hline \multicolumn{3}{|l|}{ N-Stage } \\
\hline 0 & 66 & 60.0 \\
\hline$>1$ & 44 & 40.0 \\
\hline \multicolumn{3}{|l|}{ Grade } \\
\hline 1 and 2 & 63 & 57.2 \\
\hline 3 & 45 & 40.9 \\
\hline unknown & 2 & 1.8 \\
\hline \multicolumn{3}{|l|}{ Histology } \\
\hline Invasive ductal carcinoma & 92 & 83.6 \\
\hline Invasive lobular carcinoma & 16 & 14.6 \\
\hline Other & 2 & 1.8 \\
\hline \multicolumn{3}{|l|}{ Hormone receptor status } \\
\hline Positive for either & 94 & 85.4 \\
\hline Negative for both & 16 & 14.6 \\
\hline \multicolumn{3}{|l|}{ HER2 status } \\
\hline Positive & 19 & 17.3 \\
\hline Negative & 91 & 82.7 \\
\hline \multicolumn{3}{|l|}{ Ki67 index (cut-off=14\%) } \\
\hline Low & 58 & 52.7 \\
\hline High & 52 & 47.3 \\
\hline \multicolumn{3}{|l|}{ CTC-Epithelial } \\
\hline Present & 16 & 14.6 \\
\hline Absent & 94 & 85.4 \\
\hline \multicolumn{3}{|l|}{ CTC-EMT } \\
\hline Present & 19 & 17.3 \\
\hline Absent & 92 & 82.7 \\
\hline \multicolumn{3}{|l|}{ Any CTC } \\
\hline Present & 31 & 28.2 \\
\hline Absent & 79 & 71.8 \\
\hline
\end{tabular}

HER2: Human epidermal growth factor receptor 2; EMT: epithelialmesenchymal transition; CTC: circulating tumor cells.

tPA for correlation with another four markers of blood coagulation from our previous work on the same patient population (Table III) (8). A significant correlation was found between TPA and tissue factor, D-dimers and PAI-1, while no correlation with uPA was observed.

\section{Discussion}

Presence of CTCs is associated with an increased risk of VTE. In a retrospective study of patients with metastatic breast cancer, those with any detectable CTCs were five times more likely to develop VTE compared to patients without any CTCs (7). A further study in the same population confirmed this risk and showed, in addition, that the presence of CTCs is associated with plasma D-dimers, but not fibrinogen (9). The association between CTCs and D-dimers was subsequently confirmed in patients with primary breast cancer
Table II. Association between tissue plasminogen activator (tPA) and patient/tumor characteristics.

\begin{tabular}{|c|c|c|c|c|}
\hline \multirow[b]{2}{*}{ Characteristic } & \multirow[b]{2}{*}{$\mathrm{N}$} & \multicolumn{2}{|c|}{$\mathrm{tPA}(\mathrm{ng} / \mathrm{ml})$} & \multirow[b]{2}{*}{$p$-Value } \\
\hline & & Mean & SEM & \\
\hline All & 110 & 6.81 & 3.94 & \\
\hline \multicolumn{5}{|l|}{ T-Stage } \\
\hline 1 & 67 & 6.49 & 3.42 & \multirow[t]{2}{*}{0.29} \\
\hline$>1$ & 43 & 7.30 & 4.63 & \\
\hline \multicolumn{5}{|l|}{ N-Stage } \\
\hline 0 & 66 & 6.64 & 4.43 & \multirow[t]{2}{*}{0.58} \\
\hline$>1$ & 44 & 7.06 & 3.09 & \\
\hline \multicolumn{5}{|l|}{ Grade } \\
\hline 1 and 2 & 63 & 6.27 & 3.30 & \multirow[t]{2}{*}{0.07} \\
\hline 3 & 45 & 7.65 & 4.67 & \\
\hline \multicolumn{5}{|l|}{ Histology } \\
\hline Invasive ductal carcinoma & 92 & 7.09 & 4.15 & \multirow[t]{2}{*}{0.09} \\
\hline Other & 18 & 5.36 & 2.14 & \\
\hline \multicolumn{5}{|l|}{ Hormone receptor status } \\
\hline Positive & 94 & 6.76 & 3.74 & \multirow[t]{2}{*}{0.74} \\
\hline Negative & 16 & 7.11 & 5.09 & \\
\hline \multicolumn{5}{|l|}{ HER2 status } \\
\hline Positive & 19 & 6.76 & 4.01 & \multirow[t]{2}{*}{0.95} \\
\hline Negative & 91 & 6.82 & 3.79 & \\
\hline \multicolumn{5}{|l|}{ Ki 67 (cut-off 14\%) } \\
\hline Low & 58 & 6.36 & 3.30 & \multirow[t]{2}{*}{0.21} \\
\hline High & 52 & 7.30 & 4.53 & \\
\hline \multicolumn{5}{|l|}{ Ki 67 (cut-off 20\%) } \\
\hline Low & 66 & 6.59 & 3.94 & \multirow[t]{2}{*}{0.48} \\
\hline High & 44 & 7.13 & 3.96 & \\
\hline \multicolumn{5}{|l|}{ CTC-Epithelial } \\
\hline Positive & 16 & 5.40 & 3.34 & \multirow[t]{2}{*}{0.12} \\
\hline Negative & 94 & 7.05 & 4.00 & \\
\hline \multicolumn{5}{|l|}{ CTC-EMT } \\
\hline Positive & 19 & 8.28 & 5.35 & \multirow[t]{2}{*}{0.07} \\
\hline Negative & 92 & 6.50 & 3.53 & \\
\hline \multicolumn{5}{|l|}{ CTC Any } \\
\hline Positive & 31 & 7.34 & 4.88 & \multirow[t]{2}{*}{0.38} \\
\hline Negative & 79 & 6.81 & 3.94 & \\
\hline
\end{tabular}

HER2: Human epidermal growth factor receptor 2; EMT, epithelialmesenchymal transition; CTC: circulating tumor cells; SEM: standard error of the mean.

(8). Such patients with CTCs had a significantly higher mean plasma D-dimer concentration than those without CTCs (632.4 vs. $365.4 \mathrm{ng} / \mathrm{ml}, p<0.001$ ), while there was no association between plasma tissue factor and CTCs.

Tissue and uPAs catalyze the conversion of plasminogen to plasmin and, ultimately, the fibrin breakdown that leads to the production of D-dimers. The activity of tPA (and UPA) is inhibited by PAI-1 and -2. Plasmin is responsible not only for fibrin cleavage but also for the degradation of the extracellular matrix, thereby facilitating tumor invasiveness.

Several groups have demonstrated that amplification of urokinase receptor occurs in primary tumor cells and also in CTCs of patients with breast cancer and its overexpression is 
Table III. Pearson correlation between tissue plasminogen activator (tPA) and other markers of coagulation from previous work (8).

\begin{tabular}{lcccccccc}
\hline & \multicolumn{4}{c}{ CTC } & & & \\
\cline { 2 - 4 } & Epithelial & EMT & Any & TF & DD & PAI & uPA \\
\hline $\begin{array}{l}\text { Coefficient of correlation with tPA } \\
p \text {-Value }\end{array}$ & -0.15 & 0.17 & 0.08 & 0.26 & 0.24 & 0.48 & -0.04 \\
\hline
\end{tabular}

CTC: Circulating tumor cells; EMT: epithelial-mesenchymal transition; TF: tissue factor; DD: D-dimer; PAI: plasminogen activator inhibitor; uPA: urokinase-type plasminogen activator.

a negative prognostic factor $(8,10)$. Importantly from a clinical perspective, uPA/PAI-1 are not only validated negative prognostic markers, but can also partially predict the benefit from adjuvant chemotherapy in patients with early breast cancer $(13,14)$.

In this study, no correlation between CTCs and plasma tPA was found. However, a positive correlation with D-dimers, a product of tPA effects in fibrinolysis, was demonstrated. Based on our data, we propose that other signaling pathways might be associated with an increase in CTCs and coagulation activation. Annexin II, a calcium-dependent phospholipidbinding protein, together with protein S100A10, is able to accelerate tPA-dependent plasmin formation (13). Silencing annexin II expression inhibits tPA and subsequent cell migration (15). Overexpression of annexin II was correlated with poor response to neoadjuvant chemotherapy in breast cancer and is detected mostly in aggressive breast cancer subtypes $(16,17)$. In mouse models, treatment with an antibody to annexin led to a significant inhibition of breast tumor growth and to an inhibition of conversion of tPA in the tumor microenvironment (18).

Another protein involved in fibrinolysis activation is protein S100A10, which is directly responsible for plasminogen binding and activation during fibrinolysis. Binding of annexin II to S100A10 increases the affinity of S100A10 to plasminogen and tPA, enhancing tPA-dependent conversion of plasminogen (19). Moreover, overexpression of S100A10 increased the number of metastatic foci in murine fibrosacoma (20). Whether direct inhibition of one of these proteins will lead to any meaningful responses in patients with cancer will need to be answered in clinical trials.

In contrast to uPA and its role as a marker of poor prognosis in patients with breast cancer, the prognostic role of tPA is more ambiguous. Several investigators reported conflicting data, but generally higher levels of free tPA are associated with better survival, whereas PAI-1 is associated with inferior outcome for patients with breast cancer $(21,22)$.

Currently, the only therapeutic strategy influencing the coagulation-metastatic pathway is anticoagulatory treatment. Several trials have been conducted in patients with cancer with heparins and vitamin $\mathrm{K}$ antagonists. The use of prophylactic enoxaparin in patients with pancreatic cancer undergoing palliative chemotherapy significantly reduced rates of VTE. However, overall survival of both groups (with or without prophylactic enoxaparin) was similar (23). A meta-analysis performed by the Cochrane Collaboration Group did not find benefit of oral anticoagulants and suggested caution in using thromboprophylaxis with low-molecular heparins in ambulatory patients receiving chemotherapy (24, 25). Currently, no anticoagulatory prophylaxis is recommended for oncology outpatients without elevated risk of venous thromboembolic disease (26).

In conclusion, in this prospective study we found no significant association between plasma tPA and CTCs. Higher concentrations of tPA positively correlated with other markers of coagulation, such as tissue factor, D-dimers and PAI. No correlation was seen with uPA. These data suggest that the interplay of other pathways is involved in the association of CTCs and coagulation activation.

\section{Ethics Approval}

Institutional Review Board, National Cancer Institute, Bratislava, Slovakia, Protocol TRU-SK 002).

\section{Conflicts of Interest}

On behalf of all the Authors, The senior Author (MM) declares that there are no competing financial interests in relation to the work described in the article.

\section{Acknowledgements}

The Authors would like to acknowledge Zlatica Pekova for administrative support. This publication is the result of the implementation of project no. 1/0044/15 funded by the Slovak Grant Agency VEGA [VEGA 1/0044/15 to M.M., D.M., Z.C., J.M.]. The Slovak Grant Agency had no role in design, collection, analysis, data interpretation, manuscript writing and in the decision to submit the manuscript for publication. 


\section{References}

1 Khorana AA, Francis CW, Culakova E, Kuderer NM and Lyman GH: Thromboembolism is a leading cause of death in cancer patients receiving outpatient chemotherapy. J Thromb Haemost 5: 632-634, 2007.

2 Silverstein MD, Heit JA, Mohr DN, Petterson TM, O'Fallon WM and Melton LJ, 3rd: Trends in the incidence of deep vein thrombosis and pulmonary embolism: a 25 -year population-based study. Arch Intern Med 158: 585-593, 1998.

3 Nijziel MR, van Oerle R, Hillen HF and Hamulyak K: From Trousseau to angiogenesis: the link between the haemostatic system and cancer. Neth J Med 64: 403-410, 2006.

4 Lucci A, Hall CS, Lodhi AK, Bhattacharyya A, Anderson AE, Xiao L, Bedrosian I, Kuerer $\mathrm{HM}$ and Krishnamurthy S: Circulating tumour cells in non-metastatic breast cancer: a prospective study. Lancet Oncol 13: 688-695, 2012.

5 Rack B, Schindlbeck C, Juckstock J, Andergassen U, Hepp P, Zwingers T, Friedl TW, Lorenz R, Tesch H, Fasching PA, Fehm T, Schneeweiss A, Lichtenegger W, Beckmann MW, Friese K, Pantel K and Janni W: Circulating tumor cells predict survival in early average-to-high risk breast cancer patients. J Natl Cancer Inst 106: pii: dju066, 2014.

6 Mego M, Mani SA and Cristofanilli M: Molecular mechanisms of metastasis in breast cancer--clinical applications. Nat Rev Clin Oncol 7: 693-701, 2010.

7 Mego M, De Giorgi U, Broglio K, Dawood S, Valero V, Andreopoulou E, Handy B, Reuben JM and Cristofanilli M: Circulating tumour cells are associated with increased risk of venous thromboembolism in metastatic breast cancer patients. $\mathrm{Br}$ J Cancer 101: 1813-1816, 2009.

8 Mego M, Karaba M, Minarik G, Benca J, Sedlackova T, Tothova L, Vlkova B, Cierna Z, Janega P, Luha J, Gronesova P, Pindak D, Fridrichova I, Celec P, Reuben JM, Cristofanilli $M$ and Mardiak J: Relationship between circulating tumor cells, blood coagulation, and urokinase-plasminogen-activator system in early breast cancer patients. Breast J 21: 155-160, 2015.

9 Mego M, Zuo Z, Gao H, Cohen EN, Giordano A, Tin S, Anfossi S, Jackson S, Woodward W, Ueno NT, Valero V, Alvarez RH, Hortobagyi GN, Khoury JD, Cristofanilli M and Reuben JM: Circulating tumour cells are linked to plasma D-dimer levels in patients with metastatic breast cancer. Thromb Haemost 113: 593$598,2015$.

10 Chernicky CL, Yi L, Tan H and Ilan J: Tissue-type plasminogen activator is upregulated in metastatic breast cancer cells exposed to insulin-like growth factor-I. Clin Breast Cancer 6: 340-348, 2005.

11 Mego M, Cholujova D, Minarik G, Sedlackova T, Gronesova P, Karaba M, Benca J, Cingelova S, Cierna Z, Manasova D, Pindak D, Sufliarsky J, Cristofanilli M, Reuben JM and Mardiak J: CXCR4SDF-1 interaction potentially mediates trafficking of circulating tumor cells in primary breast cancer. BMC Cancer 16: 127, 2016.

12 Mego M, Cierna Z, Janega P, Karaba M, Minarik G, Benca J, Sedlackova T, Sieberova G, Gronesova P, Manasova D, Pindak D, Sufliarsky J, Danihel L, Reuben JM and Mardiak J: Relationship between circulating tumor cells and epithelial to mesenchymal transition in early breast cancer. BMC Cancer 15: 533, 2015.

13 Semov A, Moreno MJ, Onichtchenko A, Abulrob A, Ball M, Ekiel I, Pietrzynski G, Stanimirovic D and Alakhov V: Metastasis-associated protein S100A4 induces angiogenesis through interaction with annexin II and accelerated plasmin formation. J Biol Chem 280: 20833-20841, 2005.

14 Shim BS, Park KK and Choi SH: Anti-metastatic effects of fuzhengfangaitang on human fibrosarcoma cells HT1080. Am J Chin Med 31: 235-246, 2003.

15 Jeong SM, Choi YK, Kim DY, Nam TC, Kweon OK and Youn HY: Subcutaneous fibrosarcoma with low malignancy in a pig. Vet Rec 152: 720-721, 2003.

16 Chuthapisith S, Bean BE, Cowley G, Eremin JM, Samphao S, Layfield R, Kerr ID, Wiseman J, El-Sheemy M, Sreenivasan T and Eremin O: Annexins in human breast cancer: Possible predictors of pathological response to neoadjuvant chemotherapy. Eur J Cancer 45: 1274-1281, 2009.

17 Wang T, Yuan J, Zhang J, Tian R, Ji W, Zhou Y, Yang Y, Song W, Zhang F and Niu R: ANXA2 binds to STAT3 and promotes epithelial to mesenchymal transition in breast cancer cells. Oncotarget 6: 30975-30992, 2015.

18 Sharma MC, Tuszynski GP, Blackman MR and Sharma M: Longterm efficacy and downstream mechanism of anti-annexinA2 monoclonal antibody (anti-ANXA2 $\mathrm{mAb}$ ) in a pre-clinical model of aggressive human breast cancer. Cancer Lett 373: 27-35, 2016.

19 Madureira PA, Surette AP, Phipps KD, Taboski MA, Miller VA and Waisman DM: The role of the annexin A2 heterotetramer in vascular fibrinolysis. Blood 118: 4789-4797, 2011.

20 Choi KS, Fogg DK, Yoon CS and Waisman DM: p11 regulates extracellular plasmin production and invasiveness of HT1080 fibrosarcoma cells. FASEB J 17: 235-246, 2003.

21 Duggan C, Kennedy S, Kramer MD, Barnes C, Elvin P, McDermott E, O'Higgins $\mathrm{N}$ and Duffy MJ: Plasminogen activator inhibitor type 2 in breast cancer. Br J Cancer 76: 622-627, 1997.

22 de Witte JH, Sweep CG, Klijn JG, Grebenschikov N, Peters HA, Look MP, van Tienoven TH, Heuvel JJ, Bolt-De Vries J, Benraad TJ and Foekens JA: Prognostic value of tissue-type plasminogen activator (tPA) and its complex with the type-1 inhibitor (PAI-1) in breast cancer. Br J Cancer 80: 286-294, 1999.

23 Pelzer U, Opitz B, Deutschinoff G, Stauch M, Reitzig PC, Hahnfeld S, Muller L, Grunewald M, Stieler JM, Sinn M, Denecke T, Bischoff S, Oettle H, Dorken B and Riess H: Efficacy of prophylactic low-molecular weight heparin for ambulatory patients with advanced pancreatic cancer: outcomes from the CONKO-004 Trial. J Clin Oncol 33: 2028-2034, 2015.

24 Akl EA, Kahale L, Terrenato I, Neumann I, Yosuico VE, Barba M, Sperati $F$ and Schunemann H: Oral anticoagulation in patients with cancer who have no therapeutic or prophylactic indication for anticoagulation. Cochrane Database Syst Rev 2014(6): CD006466, 2014.

25 Di Nisio M, Porreca E, Otten HM and Rutjes AW: Primary prophylaxis for venous thromboembolism in ambulatory cancer patients receiving chemotherapy. Cochrane Database Syst Rev 2016(12): CD008500, 2014.

26 NCCN: Cancer-Associated Venous Thromboembolic Disease. 1.2016 [cited 13.1.2017]; Available from: https://www.nccn.org/ professionals/physician_gls/pdf/vte.pdf

Received February 18, 2017 Revised March 10, 2017 Accepted March 13, 2017 